ISSN No: 2582-0559

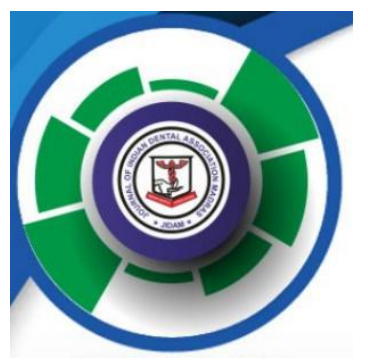

ORIGINAL STUDY

\title{
EVALUATION OF ASSOCIATION OF DIABETES MELLITUS WITH HEAD AND NECK CANCER: A CROSS-SECTIONAL STUDY
}

\author{
Dr. Amit Kumar, Dr. Gayathri Ramesh*, Dr. Vishal Chandra, Dr. Gaurav Rai**, Dr. Antima Saxena***, Dr. Abhishek \\ Anand $* * * *$ \\ Department of Oral and Maxillofacial Pathology, Rama Dental College Hospital and Research Center, Kanpur, India, \\ *Department of Dentistry, Chamarajanagar Institute of Medical Sciences, Yadapura Kasaba, Hobli, Chamrajnagar, India, \\ **Department of Oral and Maxillofacial Surgery, Buddha Institute of Dental Science and Hospitals, Kankarbagh; Patna, India, \\ ***Department of Public Health Dentistry, Institute of Dental Sciences, Siksha 'O' Anusandhan(Deemed to be University), \\ Kalinganagar, Bhubaneswar, Odisha, India****Department of dentistry, Narayan medical College and Hospital, Sasaram, India
}

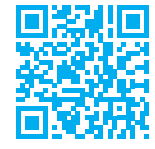

DOI:10.37841/jidam_2021_V8_I1_02

Address for correspondence

Dr. Gayathri Ramesh, MDS.,

Associate Professor, Department of Dentistry,

Chamarajanagar Institute of Medical Sciences,

Yadapura Kasaba, Hobli, Chamrajnagar 571313, India

Email id-amug3r@gmail.com

Received: 30.10.2020

First Published: 25.01.2021

Accepted: 08.01.2021

Published: 27.03.2021

\section{ABSTRACT}

INTRODUCTION: Malignant neoplasm is a major cause of death in developed countries, and its incidence continues to grow. Diabetes mellitus is a serious and leading health problem. Recent studies demonstrated that Diabetes mellitus (DM) was associated with a higher risk of Head and Neck cancer. Only a few population-based studies, especially in Asian populations, have addressed these issues. Thus, this study aimed at assessing the relationship between Diabetes mellitus and Head and Neck Cancer (HNC) in reference to their socio-economic status.

MATERIALS AND METHODS: The present study was conducted on 483 HNC patients aged above 15 years. The data was collected from patients reporting to Mahavir Cancer Institute \& Research Centre, Patna, and Rama Dental College Hospital and Research Center, Kanpur. Blood sugar level was tested to assess the status of diabetes mellitus. The demographic details such as place, social-economic status (SES), age and sex were recorded. Control group of 100 people aged above 15 years were selected with habits of using tobacco products and without any oral precancerous lesion/conditions. Odds ratios (OR) and 95\% confidence intervals (CI) were estimated using unconditional logistic regression.

RESULTS: Of 483 patients, 70 patients (14.4\%) had DM showing no overall relationship with HNC. A major number of HNC with DM was more in high socioeconomic status patients $41.7 \%(\mathrm{p}<0.05)$, showing strong association whereas for low SES it was 3.4\% ( $>>0.05)$. Out of overall Diabetes mellitus (DM), there were $77.1 \%$ of male and $22.8 \%$ were female.

CONCLUSION: Diabetes was weakly associated with HNC, but we observed evidence of a relationship with the socioeconomic group. People with HNC and low socioeconomic status showed less association with diabetes than people with high socioeconomic status.

KEY WORDS: Socioeconomic status, Diabetes mellitus, Head and Neck Cancer 


\section{INTRODUCTION}

Cancer is a name given to group of diseases characterized by the growth of abnormal cells beyond their usual boundaries that can then invade adjoining parts of the body and/or spread to other organs. Other common terms used are malignant tumors and neoplasms. Cancer affects almost any part of the body and has many anatomic and molecular subtypes which force specific management strategies.

Cancer is second main cause of death globally and accounts for 8.8 million deaths in 2015. Lung, prostate, colorectal, stomach and liver cancer are the most common types of cancer in men, while breast, colorectal, lung, cervix and stomach cancer are the most common among women. ${ }^{1}$

An increasing figure of evidence advocates that certain types of cancer are more common in people with diabetes mellitus (DM). ${ }^{2,3}$ Previous studies ${ }^{4-7}$ report elevated risks of cancers of the liver, biliary tract, pancreas, stomach, colorectum, kidney, bladder, breast, and endometrium but a decreased risk of prostate cancer. Numerous mechanisms have been projected as part of the possible carcinogenic process in DM. For example, untreated hyperglycemia may contribute to tumor growth because of the increased need for glucose to fuel proliferation in neoplasms. ${ }^{-}$In patients with DM, a single hyperglycemia-induced process in which the mitochondrial electron transport chain overproduces superoxide and reactive oxygen species is generated. ${ }^{1,8}$ Exposure to high levels of insulin and insulinlike growth factors (IGFs) in DM increases cellular proliferation and activation of the oncogenic epidermal growth factor receptor. ${ }^{9}$ Additionally, IGF and its receptors have mitogenic and antiapoptotic effects and can be source of malignant transformation. ${ }^{10,11}$

Few studies with DM have also been related with HNC, these results are still debatable. In few studies, ${ }^{12} \mathrm{DM}$ patients had an increased risk of HNC cancer, while in other studies this risk was decreased. Some studies with DM have also been associated with $\mathrm{HNC}$, these results are still controversial. ${ }^{13}$ One of the possible explanations could be given for the inverse association between DM and HNC is the difference in their socioeconomic status.

This is the first study of its kind to study the association of diabetes and SES with HNC patients with effects of habits.

\section{AIM AND OBJECTIVES}

This study aims to evaluate the association between DM, $\mathrm{HNC}$ and SES of HNC patients.

\section{MATERIALS AND METHODS}

The present study was conducted on 500 Head \& Neck cancer patients reporting at 2 different centers- - Mahavir Cancer Institute \& Research Centre, Patna, and at Rama
Dental College Hospital and Research Center, Kanpur. Out of which 17 cases was rejected due to insufficient data. The number of cases included were only 483 in this study. The control group included age and gender-matched 100patients with habits without any potentially malignant diseases (PMD). Informed consent was obtained from the patient. Ethical clearance was taken from Rama Dental College, Hospital and Research Centre, Kanpur and Mahavir Cancer Institute \& Research Centre, Patna. Inclusion criteria included patients of age group above 15 years of both genders with tobacco habits and diagnosed for oral cancer. Patients below 15 years of age, patients with any other systemic conditions and on any medication affecting blood glucose levels and patients having any PMD's were excluded.

Participants were interviewed using a standardized questionnaire to collect information about age, sex, DM and social economic status (SES), tobacco consumption, and alcohol consumption Blood samples were collected from cases and controls and fasting blood glucose levels and $2 \mathrm{hr}$ postprandial levels were estimated. Glucose oxidase peroxidase GOD/POD method was used for the estimation of glucose levels. It was based on Trinder's method. According to the American Diabetes Association (ADA) 2018 Guidelines it was considered positive for diabetes when values were $\mathrm{FPG} \geq 126 \mathrm{mg} / \mathrm{dL}(7.0 \mathrm{mmol} / \mathrm{L}) *$ (Fasting is defined as no caloric intake for $\geq 8$ hours) $P G \geq 200$ $\mathrm{mg} / \mathrm{dL}(11.1 \mathrm{mmol} / \mathrm{L})$ during OGTT $(75 \mathrm{~g}) *$ Using a glucose load containing the equivalent of $75 \mathrm{~g}$ anhydrous glucose dissolved in water.

\section{STATISTICAL ANALYSIS}

All the findings were entered in Microsoft Excel using SPSS 20.0 software and Odds ratios (OR) and 95\% CI were estimated using unconditional logistic regression. The degree of freedom between variables were also observed. Pvalue $<0.05$ represents statistically significant and $P$-value $>0.05$ represents statistically non-significant.

\section{RESULTS}

TABLE 1: Shows a total of 483 cases and 100 controls. Among these, cases with tobacco use and alcohol consumption were more likely to be males with $78.2 \%$, while females comprised of $22.1 \%$. About $50 \%$ of patients were of age between 50 to 64 years of age. Most (71.4\%) cases were of squamous cell carcinomas. Approximately $30 \%$ of cases were diagnosed with cancers of the oropharynx and hypopharynx or larynx, and $70 \%$ of the cases were diagnosed with other cancers of the oral cavity

Table 2: It was found that diabetes mellitus (DM) was not associated with $\mathrm{HNC}$ in models adjusted for age, sex, 
tobacco use, and alcohol (OR, 0.95; 95\% CI, $0.83-$ 1.08; Table 2). Results for minimally adjusted models were similar to results obtained with adjustment for age, race, sex, tobacco use and alcohol. ORs were slightly higher for women than for men, but a comparison of models with and without a product term for sex and diabetes yielded $\mathrm{p}=0.091$. Overall Diabetes mellitus (DM) cases there were $77.1 \%$ male and $22.8 \%$ were female.

Table 3: In these table HNC cases were divided in respect to their SES cases. Low SES were $71.2 \%$ of total cases in which diabetes mellitus (DM) cases were only $3.4 \%$ with pvalue being 0.771 . This showed no relationship with HNC while cases which were high of SES were $28.7 \%$, butonly
DM cases in them were $41.7 \%$. among the controls it was $17.1 \%$ with p-value of 0.021 that showed direct relationship with HNC.

\section{DISCUSSION}

483 HNC patients involved in the examination bunch were all priorly histopathological analyzed cases. Age sex and social economic status coordinated controls with harmful propensities and with no premalignant lesion were enrolled. HNC was significantly higher among patients aged between 50 to 64 years comprising around 50\%. ${ }^{14}$ Although a positive link between DM and many types of cancers

Table 1: Showing characteristics of the 483 cases and the 100 controls.

\begin{tabular}{|c|c|c|c|c|}
\hline \multirow[t]{2}{*}{ AGE } & \multicolumn{2}{|c|}{ Cases } & \multicolumn{2}{|c|}{ Controls } \\
\hline & n (483) & $\%$ & n (100) & $\%$ \\
\hline $12-39$ & 18 & 3.7 & 5 & 5 \\
\hline $40-45$ & 27 & 5.6 & 4 & 4 \\
\hline $45-49$ & 51 & 10.5 & 14 & 14 \\
\hline $50-54$ & 73 & 15.1 & 10 & 10 \\
\hline $55-59$ & 90 & 18.6 & 19 & 19 \\
\hline $60-64$ & 85 & 17.5 & 13 & 13 \\
\hline $65-69$ & 69 & 14.2 & 21 & 21 \\
\hline $70-74$ & 45 & 9.3 & 11 & 11 \\
\hline $75-94$ & 25 & 5.1 & 3 & 3 \\
\hline \multicolumn{5}{|c|}{ Sex } \\
\hline Women & 107 & 22.1 & 29 & 29 \\
\hline Men & 378 & 78.2 & 71 & 71 \\
\hline \multicolumn{5}{|c|}{ Tobacco use status } \\
\hline Never & 9 & 1.8 & 00 & 00 \\
\hline User & 474 & 98.1 & 100 & 100 \\
\hline \multicolumn{5}{|c|}{ Alcohol drinking status } \\
\hline
\end{tabular}


Amit et al: Evaluation of association of diabetes mellitus with head and neck cancer

\begin{tabular}{|c|c|c|c|c|}
\hline Never & 93 & 19.2 & 28 & 28 \\
\hline User & 390 & 80.7 & 72 & 72 \\
\hline \multicolumn{5}{|c|}{ Sub-site of tumour } \\
\hline Oral cavity & 368 & 69.3 & 00 & 00 \\
\hline $\begin{array}{c}\text { Oro- and } \\
\text { hypopharynx or } \\
\text { larynx }\end{array}$ & 148 & 30.6 & 00 & 00 \\
\hline \multicolumn{7}{|c|}{ Histology of tumour } \\
\hline Squamous cell & 388 & 80.3 & 00 & 00 \\
\hline Other & 95 & 19.6 & 00 & 23 \\
\hline
\end{tabular}

Table 2: Shows adjusted odds ratios $(\mathrm{OR})$ and $95 \%$ confidence intervals $(\mathrm{CI})$ for the association between head and neck cancer and DM

\begin{tabular}{|c|c|c|c|c|c|}
\hline DM & Case $483 \mathbf{n}(\%)$ & Control 100 n(\%) & OR & 95\% CI & p-value* \\
\hline All & $70(14.4)$ & $8(8)$ & 0.95 & $0.83-1.08$ & 0.091 \\
\hline Women & $16(22.8)$ & $1(12.5)$ & 1.06 & $0.82-1.38$ & 0.078 \\
\hline Men & $54(77.1)$ & $7(87.5)$ & 0.91 & $0.79-1.06$ & 0.052 \\
\hline
\end{tabular}

Table 3: Shows adjusted odds ratios (OR) and $95 \%$ confidence intervals (CI) for the association between head and neck cancer and DM in reference with SOCIAL ECONOMIC STATUS (SES)

\begin{tabular}{|c|c|c|c|c|c|}
\hline $\begin{array}{c}\text { SOCIAL ECONOMIC } \\
\text { STATUS (SES) n }(\%)\end{array}$ & Case 483 n $(\%)$ & $\begin{array}{c}\text { Control 100n } \\
(\%)\end{array}$ & OR & 95\% CI & p-value* $^{*}$ \\
\hline Low SES & $344(71.2)$ & $65(65)$ & 1.498 & $0.84-2.10$ & 0.025 \\
\hline Diabetes & $12(3.4)$ & $2(3.07)$ & 1.24 & $0.27-5.66$ & 0.771 \\
\hline Men & $8(66.6)$ & $2(100)$ & 3.58 & $1.17-6.94$ & 0.001 \\
\hline
\end{tabular}


Amit et al: Evaluation of association of diabetes mellitus with head and neck cancer

\begin{tabular}{|c|c|c|c|c|c|}
\hline Women & $4(33.3)$ & 0 & 1.88 & $0.10-35.3$ & 0.673 \\
\hline High SES & $139(28.7)$ & $35(35)$ & 0.75 & $0.361-1.57$ & 0.457 \\
\hline Diabetes & $58(41.7)$ & $6(17.1)$ & 1.55 & $1.070-2.24$ & 0.021 \\
\hline Men & $46(79.3)$ & $5(83.3)$ & 3.358 & $1.726-7.16$ & 0.003 \\
\hline Women & $12(20.6)$ & $1(16.6)$ & 2.25 & $0.32-19.2$ & 0.372 \\
\hline
\end{tabular}

males in India and reported that people who were wealthier,

DM exceptionally type 2 is considerably more identified with way of life. It was found that DM prevalence was high in High SES individuals in comparison to Low SES this is because DM is a life style disease which is influenced by age kind of food habbit BMI weight, central obesity and physical exercise is significant hazard factor for it $^{24}$. So, in this current investigation as a result of these realities we isolate our cases into social economic status. At the point when we isolated this information into social economic status we found that 71.2 individuals were of Low SES and 28.7\% were High SES a The explanation could be that $\mathrm{HNC}$ in India is primarily because of smokeless tobacco like khaini zarda, etc and areca nut like panmasal (This item without tobacco is known as 'panmasala' while the item with tobacco is known as 'gutkha) ${ }^{125}$ smoke tobacco like bidi (Indian explicit non-filtered cigarette) which are broadly devoured by individuals who are in Low SES like work class, vegetable vendor, cart puller and so forth due to their work pressure and because of bidi being less expensive then cigarettes. Whereas smoke tobacco like cigarette are favored by high SES individuals. In India, where oral cancer growth is a striking frequency, just short of what one-fifth (19\%) of tobacco consumed is in form of cigarettes. ${ }^{26}$

Around $26 \%$ of all adults in India use Smokeless tobacco by chewing, applying it to the teeth and gums, or by sniffing. Consumption of smokeless tobacco (SLT) (26\%) is more prevalent than various smoking tobacco. Of the $26 \%$ of all adults who use SLT, $21 \%$ use SLT every day and the other 5\% use it occasionally. A little additional than $2 \%$ of the adults who were SLT users in the past, either daily or occasionally, have since stopped such use completely. Use of SLT amid males (33\%) is higher than females (18\%); in contrast, smoking has a sharp difference between the two genders. In rural areas, $29 \%$ of adults use SLT, whereas the figure is $18 \%$ in urban areas is as per WHO in India 27

There are very few studies done similar to the present study and hence comparison in detail is limited.

Survey by Corsi and Subramanian in 2014 evaluated socioeconomic differences in smoking behavior among more educated, and having a decent job were more prone to cigarette smoking, and on the other side, people who are less educated with poor socioeconomic status had a habit of bidi smoking. This rare difference in socioeconomic inclines in consumption of two smoking habits reported among the males raises serious concern and curiosity to tackle this problem. Also, a greater concern that is ignored in many studies is growing prevalence of dual tobacco consumption amid the population and forming a tobacco quit strategy. ${ }^{28}$

Studies confirm that people consuming smokeless tobacco and bidi are at more risk of developing $\mathrm{HNC}$ then people consuming filtered cigarettes in India ${ }^{26,29,30}$ This clearly shows HNCare much more prone to people of low SES then High SES.

By the above conversation 2 focuses are clear, one DM is identified with High SES on account of their way of life and second is HNC is increasingly inclined in LOW SES individuals since utilization of smokeless tobacco and bidi smoking.

So in this current investigation, it was discovered that in $71.2 \%$ of instances of HNC were of Low SES and just 12 instances of DM were discovered that is just $3.4 \%$ p-value 0.77 demonstrating no applicable connection among HNC and DM. Very little investigation has been done till date including this subject so there isn't a lot of study accessible to talk about with results obtained $\mathrm{t}$ in this examination.

While in High SES instances of HNC were $28.7 \%$ in which $41.7 \%$ cases were of DM which show affiliation DM with HNC p-value 0.021

By this above conversation we can say that DM is way of life ailment so its less pervasive in Low SES individuals and $\mathrm{HNC}$ is progressively regular in Low SES. So when we look generally HNC isn't related with DM yet when we find in individuals With High SES where DM is basic in them $\mathrm{HNC}$ is related with DM.

This can be comprehended by pathogenesis of Diabetes mellitus and malignant growth. They are multifactorial maladies; a few potential pathophysiological pathways can add to their reliance. Nonetheless, most components fundamental the relationship among DM and the ensuing 
advancement of HNC stay hazy. A likely reason for the expanded danger of $\mathrm{HNC}$ in patients with recently analyzed DM may be shared hereditary hazard factors, DM-related metabolic morbidities (eg, hypertension and dyslipidemia), stoutness, maturing, and sex as the connection among DM and other cancers. ${ }^{32,33}$

Epigenetic adjustments of the acquired or obtained hereditary changes in disease may give another conceivable component connecting the reasons for disease and $\mathrm{DM}^{34}$ For instance, RRAD (OMIM 179503), an individual from the Ras-related GTPase superfamily, is every now and again methylated in various human dangerous tumors. ${ }^{35} \mathrm{In}$ human malignancies, RRAD may assume inverse jobs as an oncogene or a tumor silencer, contingent upon the malignancy and cell type. RRAD has been suggested to be a tumor suppressor gene in several human malignant tumors, including malignant mesothelioma, lung cancer, breast cancer, cervical cancer, prostate cancer, and NPC ${ }^{37} R R A D$ is epigenetically inactivated in NPC. Epigenetic down-regulation of $R R A D$ might disrupt the pathways downstream of the tumor suppressor p53 and lead to a malignant and aggressive phenotype. ${ }^{36}$ Conversely, RRAD translocates Grap2 and GCIP from the core to the cytoplasm, in this manner hindering the tumor silencer movement of GCIP, which happens in the nucleus. ${ }^{38}$ Consequently, RRAD may promote carcinogenesis at least in part by inhibiting GCIP-mediated tumor suppression.

One possible mechanism that links DM to the development of $\mathrm{HNC}$ is long-term exposure to hyperinsulinemia, which leads to breast cancer. Insulin is a potent growth factor that promotes proliferation and carcinogenesis in various ways, directly and through IGF. ${ }^{34-36}$ Another reasonable explanation is hyperglycemia, which may directly promote tumors: cancer cells rely on increased glucose consumption. $^{39}$ The literature also reports that hyperglycemia induces DNA damage, down-regulate the expression of antioxidants, and increases the generation of reactive oxygen species. ${ }^{40}$

This is the primary investigation corresponding the relationship of DM and HNC concerning their social monetary status and first of its sort.

\section{CONCLUSION:}

we reason that DM isn't related to HNC by and large yet as we realize that some place frequency of DM relies upon way of life of an individual and HNC is progressively inclined in Low SES individuals and these individuals have low occurrence of DM and in high SES individuals DM is related with HNC. This is just on the grounds that number instances of DM is more in High SES individuals. Further broad investigation is required with enormous example size to get increasingly productive connection.

\section{FINANCIAL SUPPORT AND SPONSORSHIP:}

Nil

\section{CONFLICTS OF INTEREST:}

There are no conflicts of interest.

\section{REFERENCES:}

[1] http://www.who.int/cancer/en/accessed on 16.9.20

[2] Basta G, Schmidt AM, De Caterina R. Advanced glycation end products and vascular inflammation: implications for accelerated atherosclerosis in diabetes. Cardiovasc Res. 2004;63(4):582-592.

[3] Sasazuki S, Charvat H, Hara A, et al; Research Group for the Development and Evaluation of Cancer Prevention Strategies in Japan. Diabetes mellitus and cancer risk: pooled analysis of eight cohort studies in Japan. Cancer Sci. 2013;104(11):1499-1507.

[4] Giovannucci E, Harlan DM, Archer MC, et al. Diabetes and cancer: a consensus report. Diabetes Care. 2010;33(7):1674-1685.

[5] Giovannucci E, Harlan DM, Archer MC, et al. Diabetes and cancer: a consensus report. $C A$ Cancer J Clin. 2010;60(4):207-221.

[6] Stott-Miller M, Chen C, Schwartz SM. Type II diabetes and metabolic syndrome in relation to head and neck squamous cell carcinoma risk: a SEER-Medicare database study. Cancer Epidemiol. 2013;37(4):428-433.

[7] Stott-Miller M, Chen C, Chuang SC, et al. History of diabetes and risk of head and neck cancer: a pooled analysis from the International Head and Neck Cancer Epidemiology Consortium. Cancer Epidemiol Biomarkers Prev. 2012;21(2):294-304.

[8] Brownlee M. Biochemistry and molecular cell biology of diabetic complications. Nature. 2001;414(6865):813-820.

[9] Adams TE, McKern NM, Ward CW. Signalling by the type 1 insulin-like growth factor receptor: interplay with the epidermal growth factor receptor. Growth Factors. 2004;22(2):89-95.

[10] Valentinis B, Baserga R. IGF-I receptor signalling in transformation and differentiation. Mol Pathol. 2001;54(3):133-137.

[11] Renehan AG, Zwahlen M, Minder C, O’Dwyer ST, Shalet SM, Egger M. Insulin-like growth 
factor (IGF)-I, IGF binding protein-3, and cancer risk: systematic review and meta-regression analysis. Lancet. 2004;363(9418):1346-1353.

[12] Gonsalves MN, Jasphin S, Karkera B, Pandit S (2015). Diabetes: risk factor for oral cancer?-A Review. Int J Adv Health Sci, 1, 25-8.

[13] Cochrane L, Ellis IR, Islam MR, Jones SJ, Macluskey M (2014). Activation of Akt at T308 and S473 in alcohol, tobacco, and HPV-induced HNSCC: is there evidence to support a prognostic or diagnostic role?. Exp Hematol Oncol, 3, 25.

[14] Mekala MR, Bangi BB, N J, Lebaka RR, Nadendla LK, GinjupallyUAssociation of Diabetes with Oral Cancer- an Enigmatic Correlation. Asian Pac J Cancer Prev. 2020 Mar 1;21(3):809-814. doi: 10.31557/APJCP.2020.21.3.809.

[15] Sasazuki S, Charvat H, Hara A, et al; Research Group for the Development and Evaluation of Cancer Prevention Strategies in Japan. Diabetes mellitus and cancer risk: pooled analysis of eight cohort studies in Japan. Cancer Sci. 2013;104(11):1499-1507.

[16]Zhou XH, Qiao Q, Zethelius B, et al; DECODE Study Group. Diabetes, prediabetes and cancer mortality. Diabetologia. 2010;53(9):1867-1876.

[17] Wideroff L, Gridley G, Mellemkjaer L, et al. Cancer incidence in a population-based cohort of patients hospitalized with diabetes mellitus in Denmark. J Natl Cancer Inst. 1997;89(18):13601365.

[18] Stott-Miller M, Chen C, Chuang SC, et al. History of diabetes and risk of head and neck cancer: a pooled analysis from the International Head and Neck Cancer Epidemiology Consortium. Cancer Epidemiol Biomarkers Prev. 2012;21(2):294-304.

[19] Lo SF, Chang SN, Muo CH, et al. Modest increase in risk of specific types of cancer types in type 2 diabetes mellitus patients. Int $J$ Cancer. 2013;132(1):182-188.

[20]Tseng CH. Oral cancer in Taiwan: is diabetes a risk factor? Clin Oral Investig. 2013;17(5):13571364.

[21] Stott-Miller M, Chen C, Schwartz SM. Type II diabetes and metabolic syndrome in relation to head and neck squamous cell carcinoma risk: a SEER-Medicare database study. Cancer Epidemiol. 2013;37(4):428-433.

[22] https://www.apa.org/topics/socioeconomicstatus/accessed on 19.9.20

[23] Suwannaphant K, Laohasiriwong W, Puttanapong N, Saengsuwan J, Phajan T. Association between
Socioeconomic Status and Diabetes Mellitus: The National Socioeconomics Survey, 2010 and 2012. J Clin Diagn Res. 2017 Jul;11(7):LC18-LC22. doi: 10.7860/JCDR/2017/28221.10286. Epub 2017 Jul 1. PMID: 28892937; PMCID: PMC5583803.

[24] Papaetis GS, Papakyriakou P, Panagiotou TN. Central obesity, type 2 diabetes and insulin: exploring a pathway full of thorns. Arch Med Sci. 2015 Jun 19;11(3):463-82. doi: 10.5114/aoms.2015.52350. PMID: 26170839; PMCID: PMC4495144.

[25] Rooban T, Elizabeth J, Anusa R, Girish KG. Health hazards of chewing areca nut and products containing areca nut. Calicut Med J 2005;3:e3.

[26] Panchamukhi PR, Woolery T, Nayantara SN. Economics of bidis in India. In: Gupta PC, Asma S, editors. Bidi Smoking and Public Health. Ministry of Health and Family Welfare, Government of India, 2008. p. 167-95

[27] WHO. Tobacco Free Initiative. Global Adult Tobacco Survey (GATS) India report 20092010. Geneva, Switzerland: World Health Organization; 2011.

[28]Corsi DJ, Subramanian SV. Divergent socioeconomic gradients in smoking by type of tobacco use in India [Short communication] Int $\mathrm{J}$ Tuberc Lung Dis. 2014;18:122-4.

[29] Madani A, H Dikshit M, Bhaduri D.Risk for oral cancer associated to smoking, smokeless and oral dip products.ijph.2012;56:57-60

[30] Balaram P, Sridhar H, Rajkumar T, Vaccarella S, Herrero R, Nandakumar A, et al. Oral cancer in southern India: The influence of smoking, drinking, paan-chewing and oral hygiene. Int $\mathbf{J}$ Cancer 2002;98:440-5

[31]Znaor A, Brennan P, Gajalakshmi V, Mathew A, Shanta V, Varghese $\mathrm{C}$, et al. Independent and combined effects of tobacco smoking, chewing and alcohol drinking on the risk of oral, pharyngeal and esophageal cancers in Indian men. Int J Cancer 2003;105:681-6.

[32] Wang P, Kang D, Cao W, Wang Y, Liu Z. Diabetes mellitus and risk of hepatocellular carcinoma: a systematic review and metaanalysis. Diabetes Metab Res Rev. 2012;28(2):109-122.

[33] Shikata K, Ninomiya T, Kiyohara Y. Diabetes mellitus and cancer risk: review of the epidemiological evidence. Cancer Sci. 2013;104(1):9-14. 
[34] Verma M. Cancer control and prevention by nutrition and epigenetic approaches. Antioxid Redox Signal. 2012;17(2):355-364.

[35] Jin Z, Feng X, Jian Q, et al. Aberrant methylation of the Ras-related associated with diabetes gene in human primary esophageal cancer. Anticancer Res. 2013;33(11):5199-5203.

[36] Mo Y, Midorikawa K, Zhang Z, et al. Promoter hypermethylation of Ras-related GTPase gene $R R A D$ inactivates a tumor suppressor function in nasopharyngeal carcinoma. Cancer Lett. 2012;323(2):147-154.

[37] Sova P, Feng Q, Geiss G, et al. Discovery of novel methylation biomarkers in cervical carcinoma by global demethylation and microarray analysis. Cancer Epidemiol Biomarkers Prev. 2006; 15(1):114-123.

[38]Lee I, Yeom SY, Lee SJ, Kang WK, Park C. A novel senescence-evasion mechanism involving Grap2 and Cyclin D interacting protein inactivation by Ras associated with diabetes in cancer cells under doxorubicin treatment. Cancer Res. 2010;70(11):4357-4365.
[39] Lee I, Yeom SY, Lee SJ, Kang WK, Park C. A novel senescence-evasion mechanism involving Grap2 and Cyclin D interacting protein inactivation by Ras associated with diabetes in cancer cells under doxorubicin treatment. Cancer Res. 2010;70(11):4357-4365.

[40] Turturro F, Friday E, Welbourne T. Hyperglycemia regulates thioredoxin-ROS activity through induction of thioredoxininteracting protein (TXNIP) in metastatic breast cancer-derived cells MDA-MB-231. BMC Cancer. 2007;7:96. 